\title{
CENTRAL PONTINE MYELINOLYSIS: A CASE REPORT
}

Chethan Belgur $\mathrm{S}^{1}$, Yugandhara $\mathrm{S}^{2}$

\section{HOW TO CITE THIS ARTICLE:}

Chethan Belgur S, Yugandhara S. "Central Pontine Myelinolysis: A Case Report". Journal of Evolution of Medical and Dental Sciences 2014; Vol. 3, Issue 15, April 14; Page: 3935-3938, DOI: 10.14260/jemds/2014/2379

ABSTRACT: Central Pontine Myelinolysis is a clinically heterogeneous condition with difficult clinical and radiological diagnosis. When the condition is found outside pons it is called extrapontine myelinolysis which is together termed as osmotic demyelination syndrome. We present a case of central pontine myelinolysis with characteristic MR imaging features.

KEYWORDS: Osmotic demyelination syndrome, Mexican hat sign.

\section{CASE REPORT:}

CLINICAL HISTORY: A fifty seven year old male presented with seven days history of agitation, delirium and altered consciousness. He had a history of recent hospitalization for the treatment of hyponatremia and jaundice.

IMAGING FINDINGS: Axial T2 FLAIR image reveals a symmetric hyperintensity involving the central pontine region, sparing the tegmentum and cortico spinal tracts resulting in a characteristic Mexican hat or bat wing configuration of hyperintensity. Coronal T2 weighted images further demonstrates central pontine involvement with sparing of periphery.

Diffusion weighted image shows restricted diffusion of the described lesion suggesting cytotoxic edema rather than vasogenic confirming the diagnosis of central pontine myelinolysis.

DISCUSSION: Central Pontine Myelinolysis is attributed to rapid correction of hyponatremia in the setting of malnutrition or alcoholism. It is usually associated when sodium level increases by more than $12 \mathrm{mmol} / \mathrm{L} / \mathrm{d} .{ }^{1}$ Rate of correction is more important than the nadir sodium concentration. ${ }^{2}$

Patients with osmotic demyelination usually present with severe electrolyte disturbances which lead to seizures and encephalopathy.

Men are affected more common than females. The mechanism of myelinolysis is thought to be linked to rupture of myelin sheaths which is caused by osmotic effects in the rapid correction of sodium levels. Oligodendrocytes are particularly sensitive for osmotic changes therefore changes that are seen with osmotic demyelination syndrome are in distribution to oligodendroglial cells. Alcoholics and malnourished are deficient in organic osmolytes and are hence at greater risk.

Imaging features lag behind the clinical presentation by about 1 to 2 weeks. However restricted diffusion in areas of myelinolysis may be seen as early as 24hours after the onset of symptoms. ${ }^{1}$ CT is less sensitive than MR imaging. Areas of myelinolysis are hypoattenuating usually located within the basilar part of pons and they lack mass effect.

Pontine tegmentum is often spared and extrapotine areas like basal ganglia and thalami may also be involved where the term osmotic demyelination syndrome is used which indicates affliction of pontine and extrapontine areas. ${ }^{1}$

On MRI, a characteristic symmetric trident or 'Mexican hat' shaped hyperintensity is seen in the central pons on the T2 weighted and FLAIR MR Images. This area is hypointense on T1 weighted 


\section{CASE REPORT}

image. ${ }^{3}$ Demyelination sparing the tegmentum and corticospinal tracts results in bilateral ventral paramedian foci of normal signal providing the Mexican hat sign.

DWI and apparent diffusion coefficient (ADC) values are very useful in distinguishing conditions which may be confused with Osmotic demyelination syndrome, e.g. brain tumors, encephalomyelitis, and multiple sclerosis. ${ }^{3}$

Lower-than-normal ADC values are associated with cytotoxic (intracellular) edema, and higher-than-normal ADC values are associated with vasogenic (extracellular) edema. ${ }^{4}$

Some authors assert that hyperintense lesions on DW MRI associated with low ADC values help to differentiate CPM from the other pontine disorders described above. It has also been proposed that if the ADC values are either normal in the presence of increased signal on $\mathrm{T}_{2}$-weighted MRI, or clear to normal rapidly, the prognosis for recovery is better. ${ }^{4}$

The most important step in CPM is mainly support the management of CPM is recognizing the patient at risk and preventing rapid correction of hyponatremia. Once the diagnosis is made the management of CPM is mainly supportive while preventing secondary complications.

FINAL DIAGNOSIS: Central Pontine Myelinolysis

\section{DIFFERENTIAL DIAGNOSIS:}

1. Multiple sclerosis

2. Pontine tumours

\section{ABBREVIATIONS:}

CPM: Central Pontine Myelinolysis

ADC: Apparent Diffusion Coefficient

\section{REFERENCES:}

1. Stephanie A. Howard, Justine A. Barletta, Roman A. Klufas, Ali Saad, Umberto De Girolami et al. Best Cases from the AFIP -Osmotic Demyelination Syndrome. Radio Graphics 2009; 29:933-938.

2. Jonathan Graff-Radford, Jennifer E. Fugate, Timothy J. Kaufmann, Jay N. Mandrekar, and Alejandro A. Rabinstein. Clinical and radiological correlations of central pontine myelinolysis Syndrome. Mayo Clinic Proc. Nov 2011; 86(11): 1063-1067

3. Islam G Dhillon et al. MRI in Osmotic Demyelination: The "Mexican Hat" Sign. The Internet Journal of Radiology. 2009 Volume 12 Number1.

4. Robin A. Hurley, Christopher M. Filley, Katherine H. Taber et al. Central Pontine Myelinolysis: A Metabolic Disorder of Myelin. The Journal of Neuropsychiatry and Clinical Neurosciences 2011; 23: 369-374. 


\section{CASE REPORT}

Figure 1: Axial T2 FLAIR image demonstrates a symmetric hyperintensity involving the central pontine region, sparing the tegmentum and cortico spinal tracts resulting in a characteristic Mexican hat or bat wing configuration of hyperintensity.

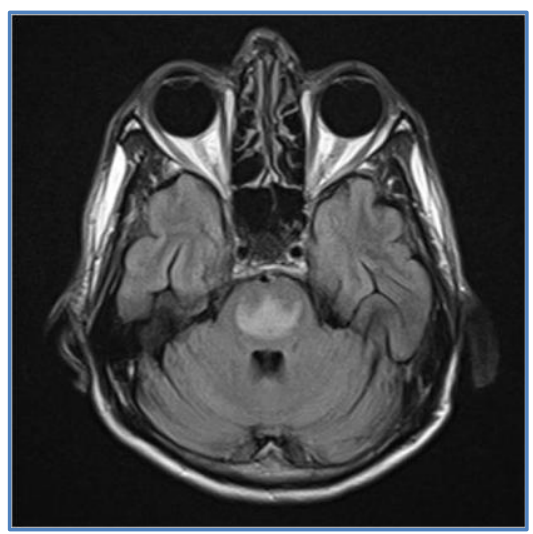

\section{Figure 1}

Figure 2: Coronal T2 weighted image demonstrates central pontine involvement with sparing of periphery.

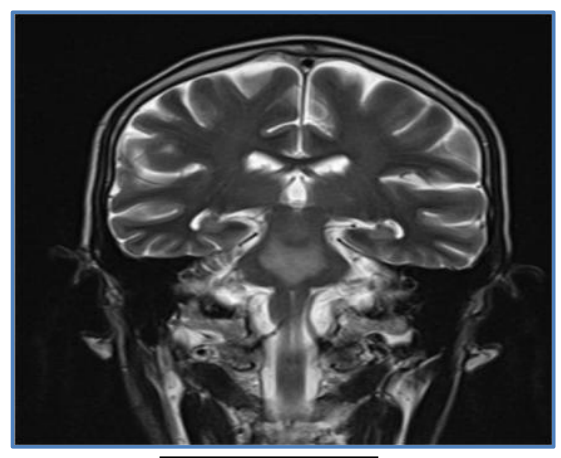

Figure 2

Figure 3: Diffusion weighted image shows restricted diffusion of the described lesion.

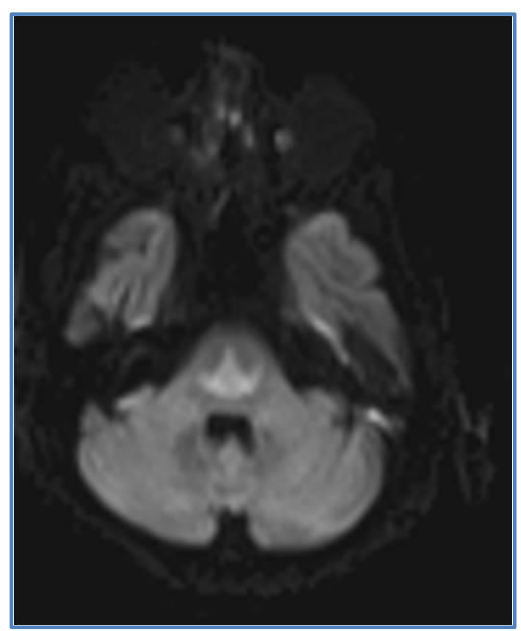

Figure 3 


\section{CASE REPORT}

\section{AUTHORS:}

1. Chethan Belgur $\mathrm{S}$.

2. Yugandhara S.

\section{PARTICULARS OF CONTRIBUTORS:}

1. Assistant Professor, Department of Radiodiagnosis, DM WIMS, Kerala.

2. Assistant Professor, Department of Radiodiagnosis, DM WIMS, Kerala.

\section{NAME ADDRESS EMAIL ID OF THE} CORRESPONDING AUTHOR:

Dr. Chethan Belgur,

Sri Maruthi Nilaya,

$5^{\text {th }}$ Cross, Rajendra Nagar,

Shimoga- 577204.

E-mail: drchethanbelagur@gmail.com

Date of Submission: 11/03/2014.

Date of Peer Review: 12/03/2014.

Date of Acceptance: 20/03/2014.

Date of Publishing: 09/04/2014. 